\title{
NUMERICAL DETERMINATION OF 3D TEMPERATURE FIELDS IN STEEL JOINTS
}

\author{
Jean-Marc FRANSSEN, Luc BRAUWERS \\ Univ. of Liege, 1, Chemin des Chevreuils, 4000, Liège 1, Belgium \\ jm.franssen@ulg.ac.be
}

\begin{abstract}
A numerical study was undertaken to investigate the temperature field in steel joints and to compare the temperatures in the joints to the temperatures of the adjacent steel members in the hypothesis that the thermal protection is the same on the joint and in the members.

Very brief information is given on the numerical model, supplemented with parametric studies made in order to determine the required level of discretisation in the time and in the space domain. A simplified assumption for representing the thermal insulation is also discussed and validated.

Different numerical analyses are performed, with a variation of the following parameters:

- Type of joints, from very simple to more complex configurations, with welds and/or bolts, all of them representing joints between elements located in the same plane.

- Unprotected joints or protected by one sprayed material.

- ISO, Hydrocarbon or one natural fire scenario.

The fact that the thermal attack from the fire might be less severe because the joints are usually located in the corner of the compartment is not taken into account.
\end{abstract}

KEYWORDS: temperature, steel, joints, numerical analysis, $3 D$ 


\section{INTRODUCTION}

It is usually assumed that the joints in steel construction don't require any special verification as far as their thermal insulation is at least equal to the insulation applied on the adjacent members.

For example, in the most recent draft of Eurocode 3 [1], it is written concerning connections:

The resistance of category $A$ and $B$ connections may be assumed to be sufficient provided that the two following conditions are met:

1) the thermal resistance $\left(d_{\mathrm{f}} / \lambda_{\mathrm{f}}\right)_{\mathrm{c}}$ of the fite protection of the connection is not less than the minimum value of the thermal resistance $\left(d_{\mathrm{f}} / \lambda_{\mathrm{f}}\right)_{\mathrm{m}}$ of the fire protection of any of the steel members joined by that connection, whère:

$d_{\mathrm{f}}$ is the thickness of the fire protection material - take $d_{\mathrm{f}}=0$ for unprotected members;

$\lambda_{\mathrm{f}} \quad$ is the effective thermal conductivity of the fire protection material.

2) the utilisation $E_{d, f i} / R_{d}$ of the connection is not higher than the maximum value of the utilisation of any of the steel members joined by that connection.

Also, concerning members verification, it is written in [1]:

Net-section failure at fastener holes need not be considered, provided that there is a fastener in each hole, because the steel temperature is lower at connections due to the presence of additional material.

The assumption behind these rules is clearly that the temperature in the joint will be lower than the temperature in the members because there is a higher mass concentration in the joint. In fact, the local massivity, i.e. the ratio between the mass and the exposed surface, is the leading parameter and not only the mass. A numerical study was thus undertaken to see whether the assumption of lower temperature in the joints is systematically valid.

\section{SCOPE}

Only steel connections are considered, i.e. no concrete slab is present. Three fire scenario are considered, namely the ISO 834 fire curve, the hydrocarbon fire curve and one natural fire curve taken from Eurocode 1 [2] with a heating phase duration of 31 minutes and a maximum temperature of $773^{\circ} \mathrm{C}$. Each joint is analysed as unprotected, then as thermally protected.

\section{HYPOTHESES}

The thermal properties of steel are taken from Eurocode 3 [3]. The boundary conditions are taken from Eurocode 1 [2], i.e. $h=25 \mathrm{~W} / \mathrm{mK}$ for convection and $\varepsilon^{*}=0.50$ for radiation.

Thermal contact is assumed to be perfect between any 2 adjacent objects; there is no thermal resistance produced by an eventual imperfect contact.

The temperature field is determined with the software SAFIR [4], using linear finite elements and an Euler-Backward implicit time integration scheme $(\theta=0.90)$. 


\section{PRELIMINARY STUDY ON THE DISCRETISATION}

It is important to know what is the required level of refinement in the discretisation, both in the time as well as in the space domain; the precision must not be excessively deteriorated by a too crude approximation, but the calculation time has to be maintained within reasonable limits. Figure 1, for example, shows the isotherms after 30 minutes of ISO fire in a bolt passing through a $40 \mathrm{~mm}$ steel plate (the head and the screw are hexagonal, and the extremity of the cylindrical shank has also be approximated as hexagonal, which allows discretising only a $30^{\circ}$ sector). Figure 2 shows that a very similar temperature pattern can be obtained with a cruder discretisation in which each extremity of the bolt is represented by a single finite element. On the other hand, if the bolt is not represented at all and only the steel plate is represented, the hot spot that appears near the bolt on Figure 1 and Figure 2 will not appear and this cannot be accepted.

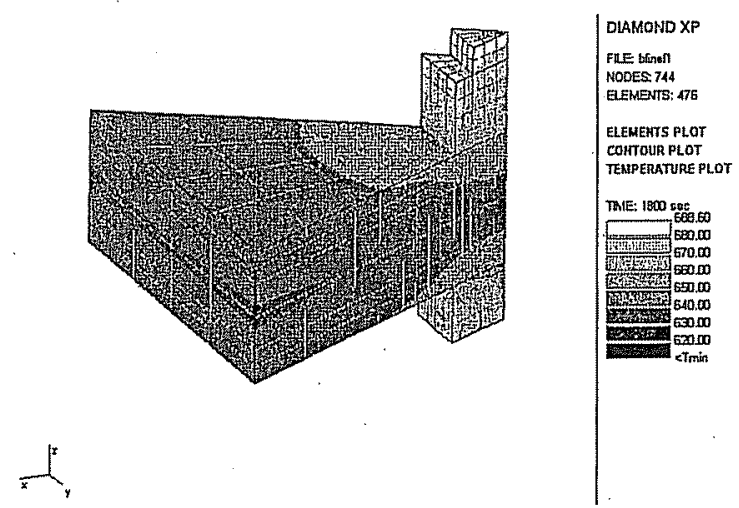

Figure 1 : fine discretisation for a bolt

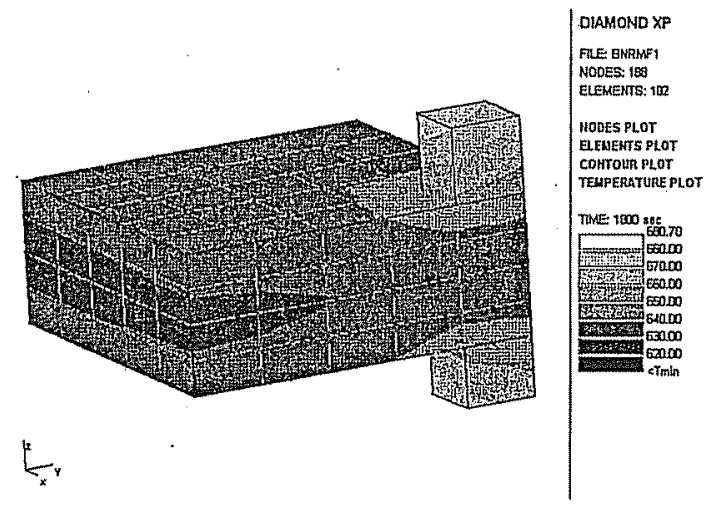

Figure 2 : discretisation used for a bolt

A simplified modelling is also proposed for the protection, that allows a significant reduction in the time for calculation, but above all in the time required for discretising. This simplification is explained here in a 2D situation for simplicity reasons.

The most general way to take the thermal insulation into account is to represent it explicitly by some layers of finite elements, see Figure 3. Of course, this requires a large number of additional finite elements and this has severe consequences on the time required for calculation but even more on the time required for building the model. In fact, if the thermal protection is provided by a lightweight material with a negligible specific heat, the thermal resistance $R$ provided by the layer of insulating material can be evaluated, in the uniaxial situation that prevails for most parts of the steel sections, by the following equation:

$$
R=\frac{1}{\alpha_{p}}+\frac{t_{p}}{\lambda_{p}}
$$

where $t_{p}$ thickness of the protection layer,

$\lambda_{p}$ thermal conductivity of the protection material,

$\alpha_{p} \quad$ coefficient of heat exchange at the surface of the protection, see equation 2 .

$\alpha_{p}=h_{p}+\varepsilon_{p}^{*} \sigma_{0}\left(T_{g}^{3}+T_{g}^{2} T_{p}+T_{g} T_{p}^{2}+T_{p}^{8}\right)$ 
where $h_{p}$ coefficient of convection,

$\varepsilon_{p}^{*}$. relative emissivity,

$\sigma_{0} \quad$ Stefan-Boltzman constant,

$T_{g}$ temperature of the gas,

$T_{p} \quad$ temperature at the surface of the protection.

In fact, it can be shown that in most commonly used thermal protections, the surface resistance is negligible in equation 1 when compared to the resistance to conduction provided by the thermal protection. Equation 3 is therefore a good approximation of equation 1 ; replacing equation 1 by equation 3 amounts to assume that the temperature at the surface of the insulation is equal to the te mperature of the gas.

$$
R=\frac{t_{p}}{\lambda_{p}}
$$

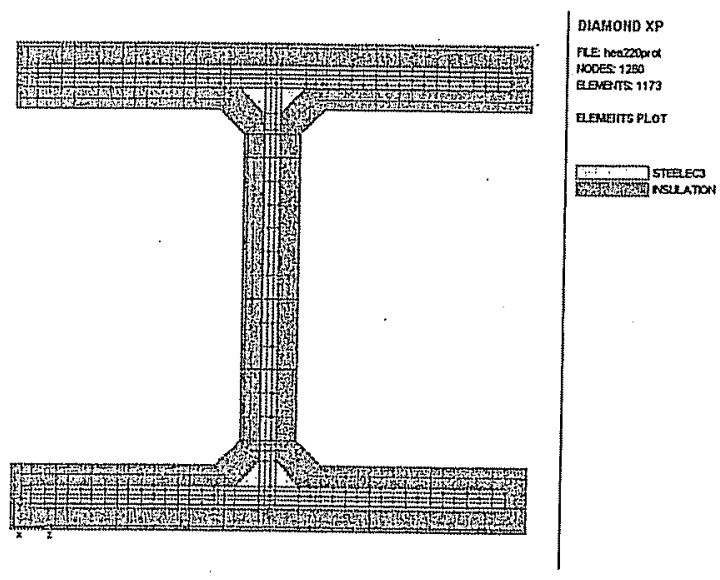

Figure 3 : protection represented

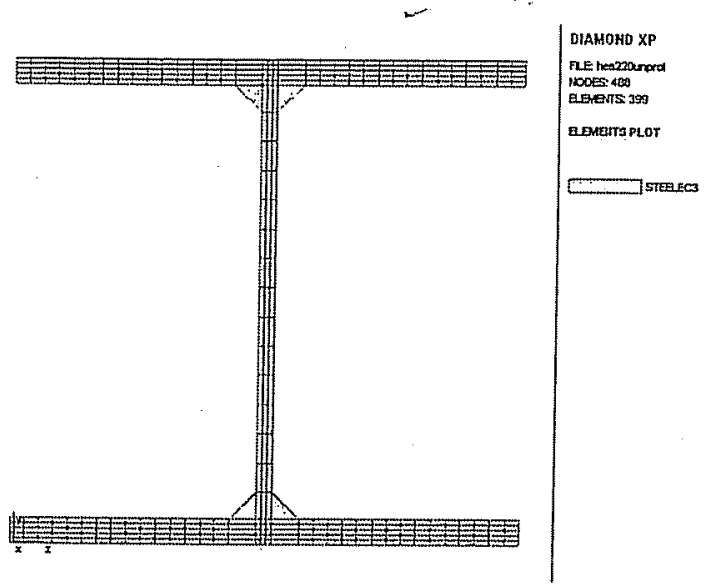

Figure 4 : equivalent protection

In an unprotected section, the surface resistance on the steel plate $1 / \alpha_{\mathrm{s}}$ is the only thermal resistance with $\alpha_{\mathrm{s}}$ given by equation 4 .

$$
\alpha_{s}=h_{s}+\varepsilon_{s}^{*} \sigma_{0}\left(T_{g}^{3}+T_{g}^{2} T_{s}+T_{g} T_{s}^{2}+T_{s}^{3}\right)
$$

It is therefore possible consider the effect of the insulation and yet to represent only a non-insulated section, see Figure 4, provided that the surface properties of steel are adapted accordingly. The simplest solution is given by equation 5 .

$$
\begin{aligned}
\varepsilon_{s}^{*} & =0 \\
\frac{1}{h_{s}} & =\frac{t_{p}}{\lambda_{p}}
\end{aligned}
$$

For example, in order to model a $10 \mathrm{~mm}$ layer of insulation with a thermal conductivity $\lambda_{p}=0.04 \mathrm{~W} / \mathrm{mK}$, it is possible to use an unprotected section with an emissivity equal to 0 and a convection factor equal to $4 \mathrm{~W} / \mathrm{m}^{2} \mathrm{~K}$. This has been done for the HEA220 represented on Figure 3 and Figure 4 and the comparison in the obtained temperatures is given in Figure 5. 


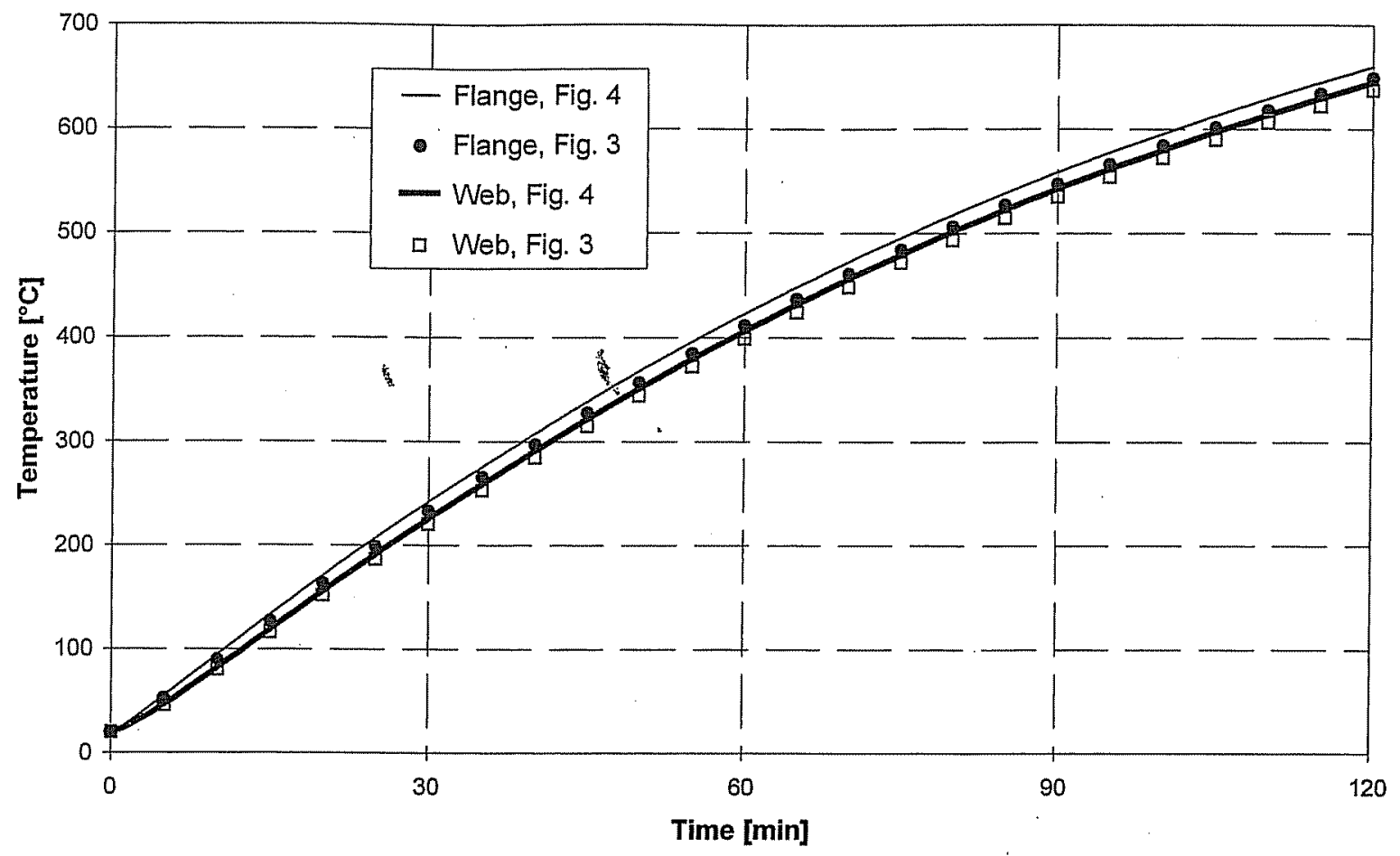

Figure 5 : comparison between represented protection and equivalent protection

As far as the time step is concerned, it was shown by comparisons with a very small time step that the relative error on the temperature does not exceed $0.5 \%$ with a rather large time step of 60 seconds in a protected joint and 12 seconds in an unprotected joint. The relative temperature difference between two different locations in a joint is not influenced by the time step.

\section{FIN EFFECT FROM THE BOLT}

A fin effect is produced when an object having a low mass but a high surface is in contact with a massif object. It is sometimes referred to as the "extended surface" effect. This effect is particularly used in the heat exchanger technology where a large number of thin plates are welded to the body that has to exchange heat as efficiently as possible with the environment; because of the high surface of the plates and because of the low contact thermal resistance between the plates and the object, the heat exchange is increased by the plates.

In a joint submitted to the action of the fire, the bolts might play the role of fins for the plates that they are connecting. This effect is in fact visible on Figure 1 and Figure 2. Under which conditions will this appear and how significant is this effect?

This effect has been analysed in different geometrical configurations, different fire scenarios and different protection configurations. Figure 6 and Figure 7, for example, refer to the situation after 20 minutes of ISO fire in an unprotected joint with an M27 bolt connecting 2 steel plates of $20 \mathrm{~mm}$ (Figure 6) and $8 \mathrm{~mm}$ (Figure 7). In each case, the length of the screw extending beyond the nut is $10 \mathrm{~mm}$. 


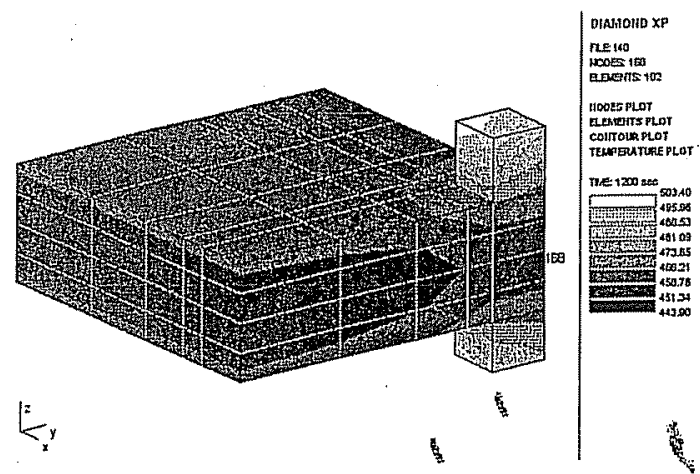

Figure $6:$ M27 bolt on $2 \times 20 \mathrm{~mm}$ plates

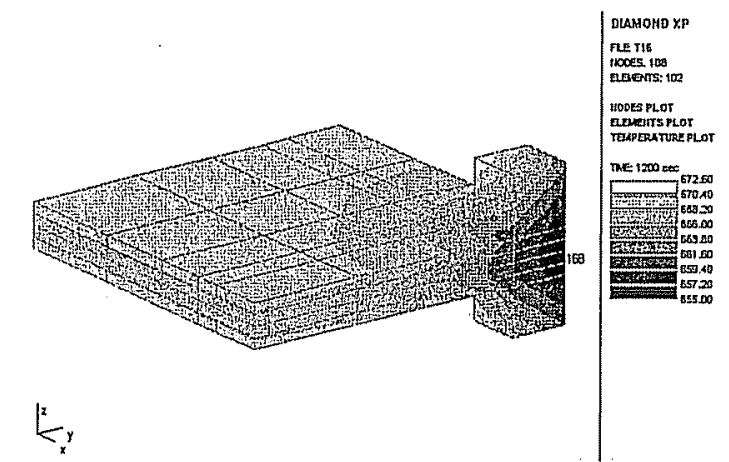

Figure 7 : M27 bolt on $2 \times 8 \mathrm{~mm}$ plates

One temperature that is significant for the strength of the connection is the temperature in the shear plane in the bolt (node 168). This temperature of the bolt can be compared to the temperature in the plate as calculated away from the bolt, i.e. neglecting the influence of the bolt. It can be observed that the bolt on thick plates makes the temperature in the bolt higher than the temperature of the plate, see Figure 6 , whereas the same bolt on thin plates makes the temperature in the bolt lower than the temperature in the plate, see Figure 7. What was a fin for a massive object becomes a protection for the thin object.

From all the analyses performed, it appears that the significant parameter is the ratio $d / 2 t$ between the diameter of the screw and the total thickness of plates that is significant; for $d / 2 t<1$, the bolt is a hot spot whereas, for $d / 2 t>1$, the bolt is a cold spot.

Although the second situation might not be the most common one, it can be immediately accepted in this case to neglect the effect of the bolt when evaluating the temperature, because this is on the safe side.

For the first situation, must the local effect of the bolt absolutely be taken into? In fact, it appears that the local increase of temperature caused by the presence of the bolt is quantitatively very limited. This is shown on Figure 8 that represents the evolution of the temperature in the centre of the bolt (node 168, see Figure 6) and of the temperature in the centre of the plate far away from the bolt. This figure has been drawn for the case in which the highest differences can be observed, namely in an unprotected joint, with the very fast hydrocarbon fire curve and with a excessively long screw extending $40 \mathrm{~mm}$ beyond the nut. The amount by which the temperature is underestimated if calculated with the massivity of the 2 plates is very limited, with a peak value for $\Delta \mathrm{T}$ of $36^{\circ} \mathrm{C}$ after 18 minutes. For any other time within the fire or any other configuration, the difference would be less than $36^{\circ} \mathrm{C}$. By configuration, we refer here to the combination fire-protection-geometry.

The effects of the configuration on the fin effects are:

- The faster the fire, the more pronounced the fin effect; with slower fires, time has a tendency to render the temperature field more homogeneous. This is why the effect is more pronounced with a hydrocarbon fire than with the ISO fire.

- The effect is reversed during the cooling down phase of a natural fire; if the fin effect is increasing the heat exchange with the environment, it will accelerate the heating as well as the cooling and, hence, a hot spot during heating will turn in a cold spot during the cooling. 
- Thermal protection, because it slows down the temperature elevation, has also a tendency to render the situation more homogeneous.

- An excessively long screw will emphasize the fin effect on massive onbjects and the protection effect of thin objects.

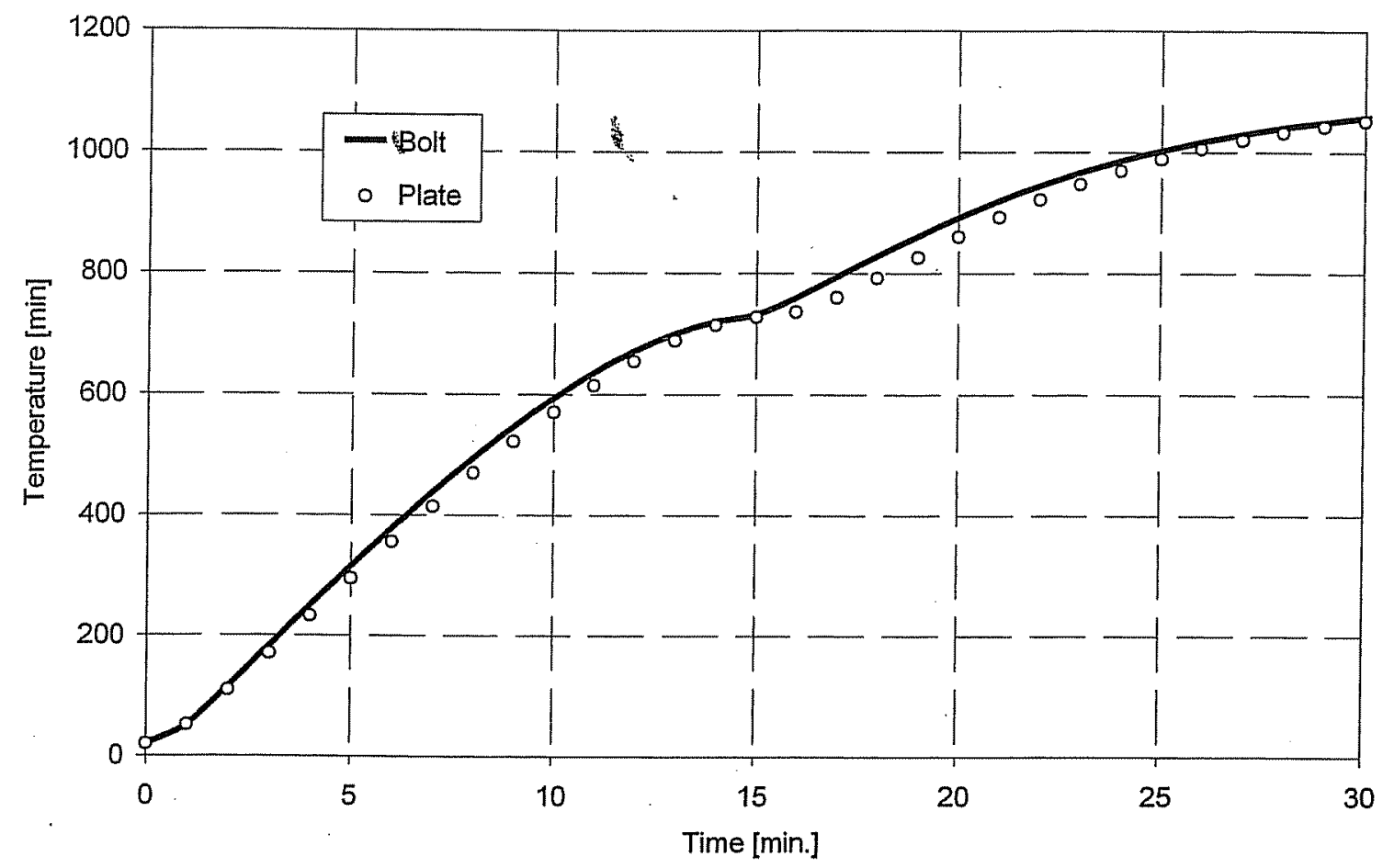

Figure 8 : M27 on $2 \times 20$ plates - hydrocarbon fire

According to the above considerations, it appears that the local effect of the bolts can really be neglected when evaluating the temperature distribution in a joint.

\section{EFFECT OF THE WELDS}

A geometry commonly encountered in joints is when a stiffener is made of a thin plate welded on a thicker plate. The weld in this case has several different effects: a) it decreases locally the area of the surface that is exchanging heat with the environment, $b$ ) it increases locally the mass of material to be heated, c) it increases the surface available for the heat to pass by conduction from the thin plate to the thick plate.

The influence of the weld can also be analysed in a 2D model, see Figure 9, Figure 10 and Figure 11. They refer to a $20 \mathrm{~mm}$ thick plate (half thickness represented here for symmetry reason) welded on a $40 \mathrm{~mm}$ plate with a $5 \mathrm{~mm}$ weld. The fire is the hydrocarbon fire and the section is not thermally protected. The figures seem to indicate that a very fine discretisation is not really required, but that the weld absolutely has to be taken into account. In fact, the difference in temperatures between Figure 10 and Figure 11 are not quantitatively so important and a discretisation without the weld could represent an acceptable approximation. 


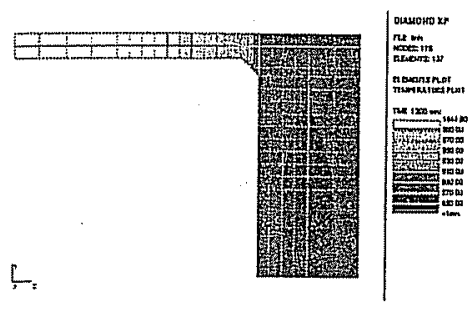

Figure 9 : fine discretisation

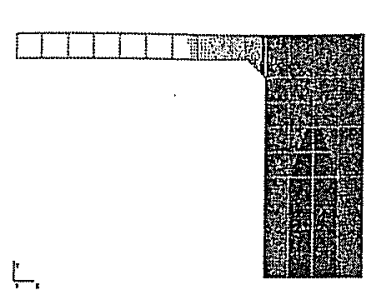

Figure 10 : normal discretisation

\section{TEMPERATURE OF THE WELD \\ WELD}

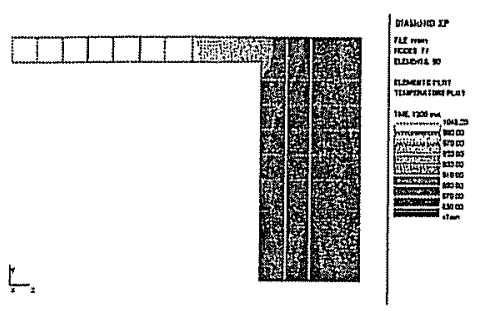

Figure 11 : weld not represented

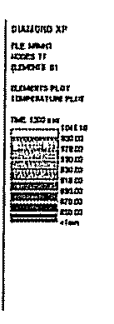

represented

Figure 12 refers to the same geometry as seen in Figure 9, but now for an ISO fire. The upper curve shows the temperature evolution as calculated by SAFIR in the thin plate far away from the connection. It can be observed that the curve corresponds exactly to the curve that is calculated with the simple equation of Eurocode 3 in the hypotheses of a uniform temperature in this plate. The same holds for the lower curve that depicts the evolution in the thick plate. The central curve corresponds to the temperature in the weld. It is closer to the temperature of the thick plate than to the temperature of the thin plate. It would be very uneconomical to design the weld based on the temperature of the thin plate, yet unsafe to design on the bases of the temperature in the thick plate.

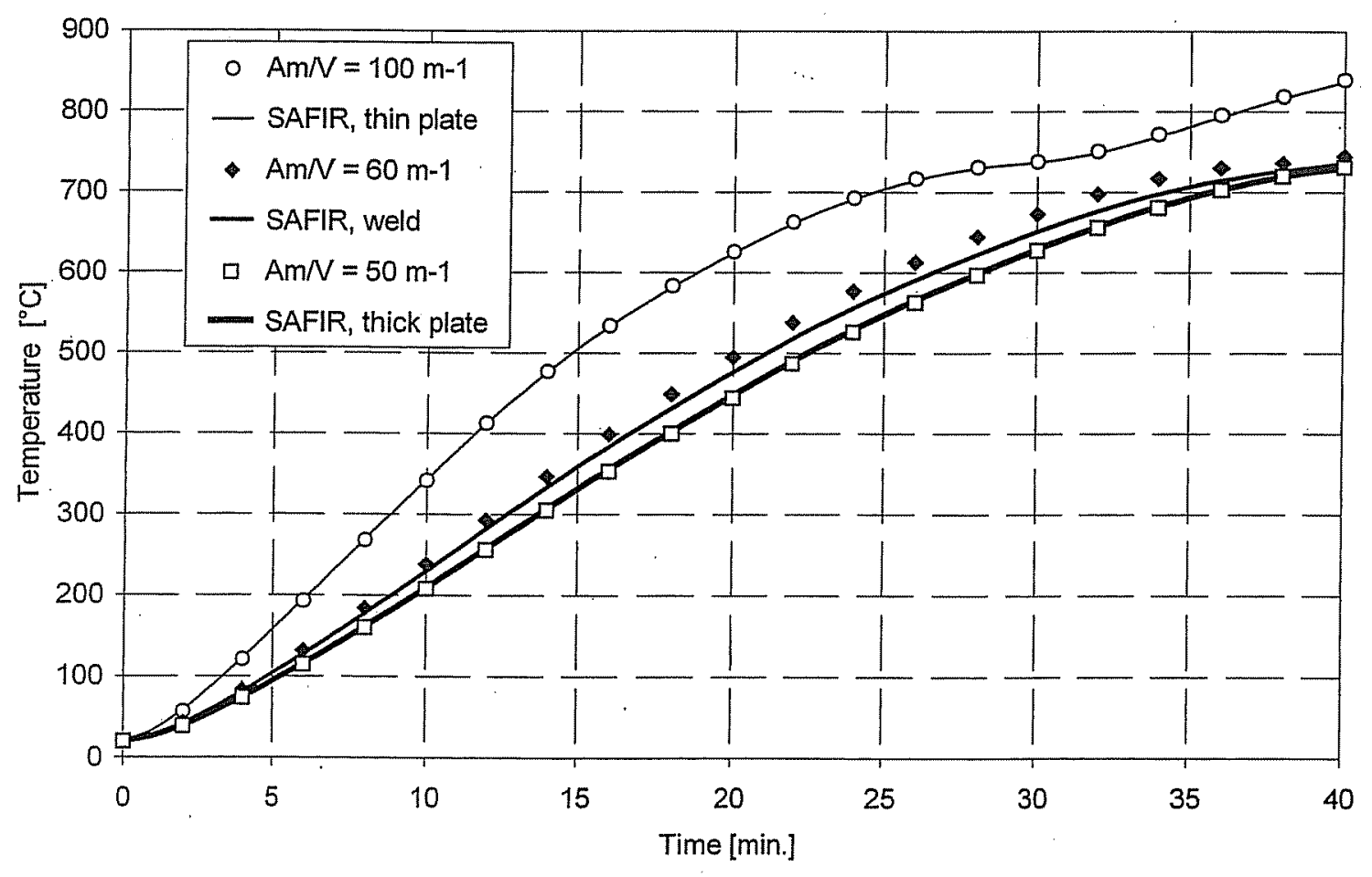

Figure 12 : evolution of the temperature under ISO fire 


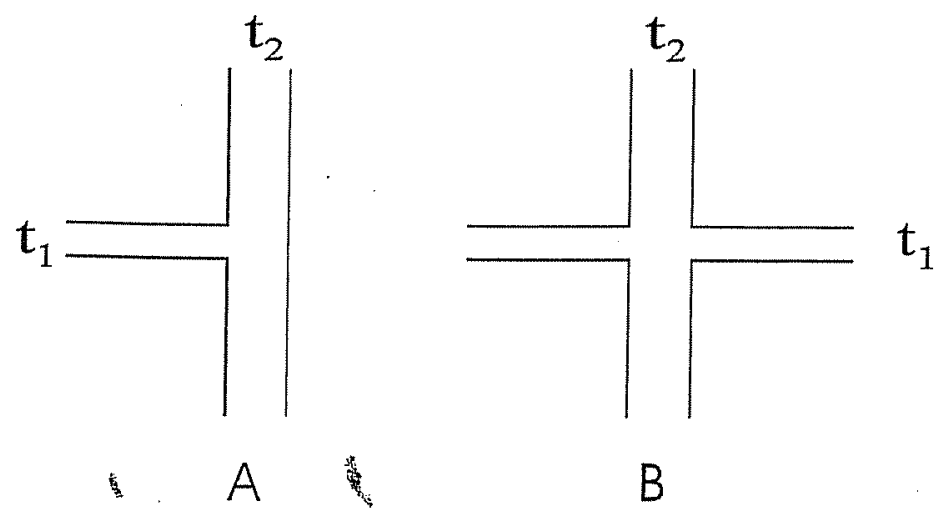

Figure 13 : two different configurations

A good and safe approximation is obtained if one considers the thermal massivity in this region as the one being calculated in the hypothesis of Figure 13-A where a unit length is considered in each direction from the weld. The massivity is then calculated according to equation 7.

$$
\frac{A_{m}}{V}=\frac{6}{t_{1}+2 t_{2}}
$$

In this particular case, equation 7 yields $A_{m} / V=6 /(0.02+2 \times 0.04)=60 \mathrm{~m}^{-1}$ and it can be observed on Figure 12 that the temperature calculated on the base of this thermal massivity is an acceptable approximation of the numerical solution.

In the geometrical configuration depicted by Figure 13-B, the temperature in the weld is somewhat higher. It can be safely estimated on the base of the thermal massivity evaluated by equation 8 .

$$
\frac{A_{m}}{V}=\frac{8}{2 t_{1}+2 t_{2}}=\frac{4}{t_{1}+t_{2}}
$$

In this case, it yields $A_{m} / V=4 /(0.02+0.04)=67 \mathrm{~m}^{-1}$

In fact, a more precise equation could be written instead of equation 7 . Changing the coefficient applied to $t_{2}$ in this equation from 2 to $9 / 4$ yields as a consequence that the temperature of the weld is the same as the temperature of the thick plate if $t_{1}=0.75 t_{2}$ as observed in the numerical calculations. In this case, this would lead to $A_{m} / V=55 \mathrm{~m}^{-1}$ for the weld and the temperature calculated by the simple method would be somewhat colder, in fact nearly exactly the same as the temperature calculated by SAFIR. The expression of equation 7 has been kept for simplicity reasons. 


\section{D ANALYSES}

\section{Bar in tension - one cover plate}

Figure 14 shows the isotherms in an unprotected tension joint with one single cover plate after 30 minutes of ISO fire. The bars to join have a $12 \times 150 \mathrm{~mm}^{2}$ section and the 12 $\mathrm{mm}$ thick cover sheet is $352 \mathrm{~mm}$ long. One quarter of the joint only has been analysed for symmetry reasons; in fact, a total of eight bolts is used in the joint.

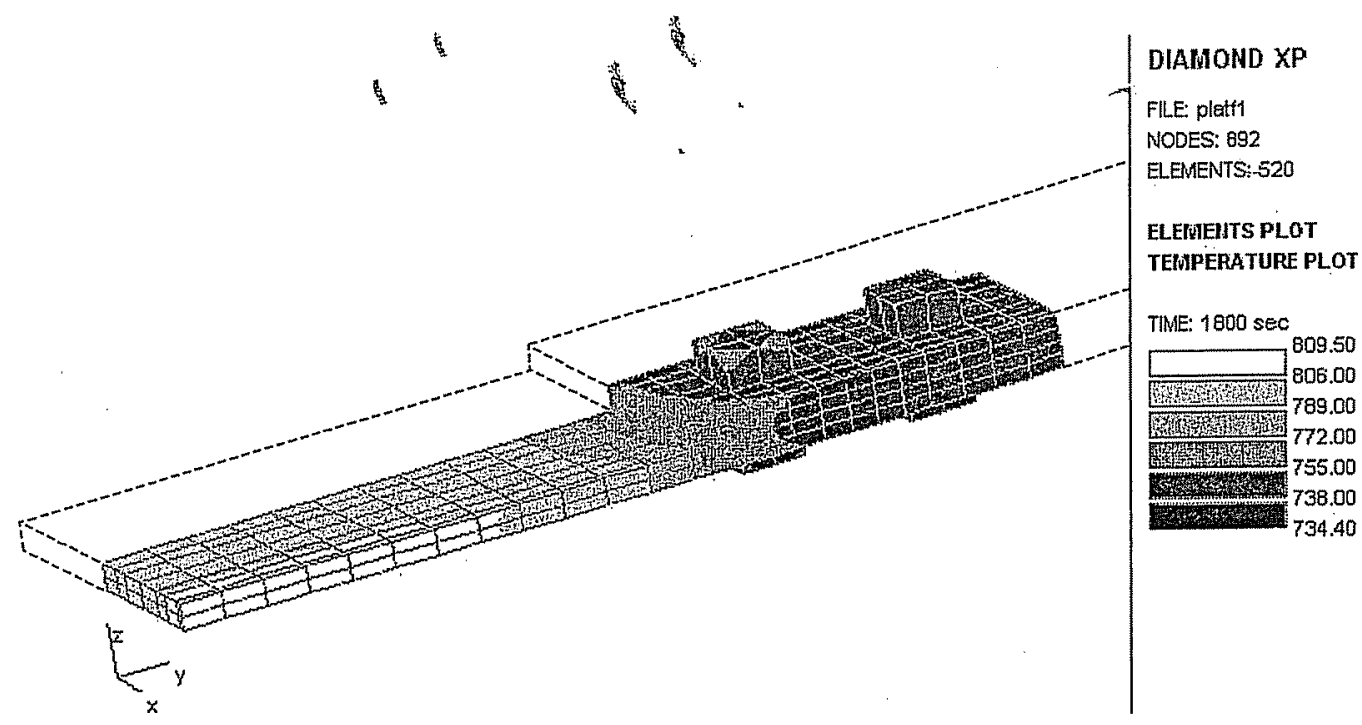

Figure 14 : bars in tension - one cover plate - unprotected

In this case, the ratio between the diameter of the bolt and the thickness of the plate is equal to $20 / 24$ and, as it is smaller than 1 , the bolts create a hot spot in the joint.

The temperature after 30 minutes calculated by the simple method using the thermal massivity of the tension plates $A_{m} / V=2(0.012+0.150) /(0.012 \times 0.150)=180 \mathrm{~m}^{-1}$ is equal to $806^{\circ} \mathrm{C}$, whereas the temperature calculated with the thermal massivity of the joint (neglecting the effect of the bolts) $A_{m} / V=2(0.150 \times 0.352+0.024 \times 0.352+0.150 \times 0.012)$ $/(0.024 \times 0.150 \times 0.352)=100 \mathrm{~m}^{-1}$ is $738^{\circ} \mathrm{C}$. These two significant temperatures are represented on the temperature scale on the right in Figure 14. It can be observed in this unprotected connection that:

1. The joint is definitively colder than the tension plates.

2. The colder zone in the tension plates near the joint has a limited extension.

3. Nearly the whole joint has a temperature that is by $20^{\circ} \mathrm{C}$ in excess of the temperature that is calculated by the simple method using the massivity of the joint.

Figure 15 refers to the same joint, now thermally protected. The temperatures calculated by the simple method after 90 minutes of exposure are $523^{\circ} \mathrm{C}$ in the tension bars away from the joint and $367^{\circ} \mathrm{C}$ in the joint. From the isotherms on the figure, it can be observed that:

1. The joint is still colder than the tension plates.

2. The colder zone in the tension plates near the joint has extends to a longer distance.

3. The temperature at any point in the joint is at least $410^{\circ} \mathrm{C}$. The temperature in the bolt that is closest to the bars is $425^{\circ} \mathrm{C}$. This means that the temperature in the joint is 40 to 
$60^{\circ} \mathrm{C}$ higher than temperature that is calculated by the simple method using the massivity of the joint.

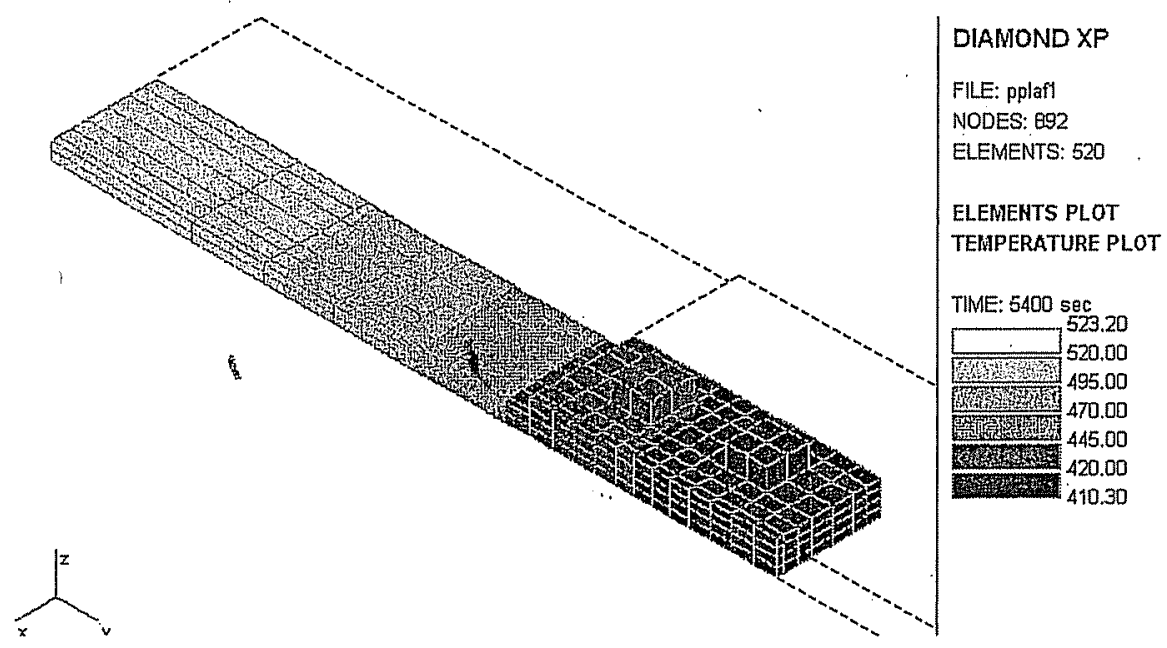

Figure 15 : bar in tension - one cover plate - thermally protected

The observations that have been made here in the simplest case of a joint with 2 different thickness, and the difference between the insulated or non insulated joint, will in fact generally be observed in all the more complex geometries that can be analysed. This is illustrated in the next sections.

\section{Bars in tension - two cover plates}

Figure 16 is a joint for the same bars as presented in Figure 14, i.e. non protected, but now with two symmetrically located cover plates with a thickness of $6 \mathrm{~mm}$ each. The same observations can be made here, namely; a cold zone of limited extension in the bar close to the joint; a joint that is significantly colder than the bar; the temperature in the joint somewhat higher than the temperature of $738^{\circ} \mathrm{C}$ than can be calculated by the simple method on the base of the massivity of the joint.

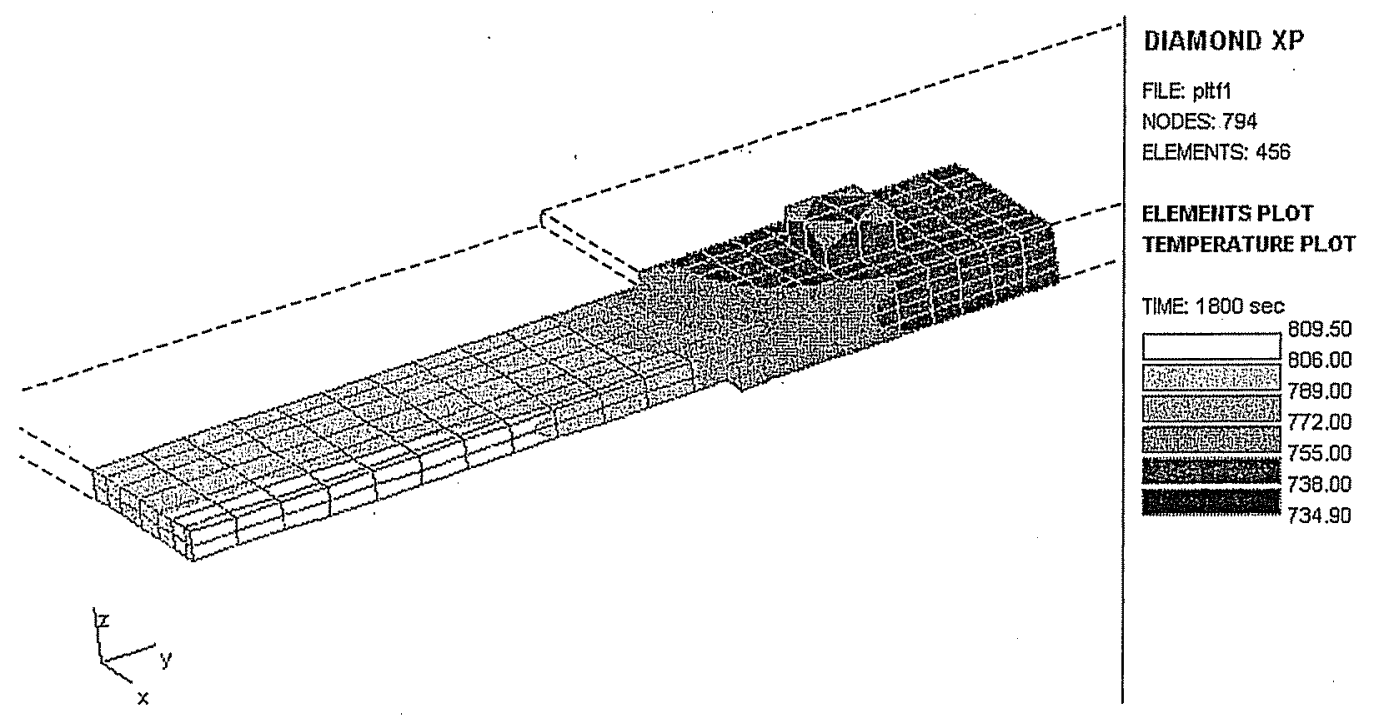

Figure 16 : bars in tension - two cover plates - unprotected 


\section{Bars in tension - net or whole section}

It is written in Eurocode 3 [1] that net-section failure at fasteners holes need not be considered because of the presence of additional material.

Figure 17 shows the evolution of the temperature in the thermally protected joint depicted in Figure 16 at the level of the bolt, first as calculated by SAFIR, then as calculated on the base of the local massivity in the joint, $97 \mathrm{~m}^{-1}$, and it is seen that this is unsafe, and finally on the base of the massivity of the connected bars, $180 \mathrm{~m}^{-1}$, and it is seen that this is safe.

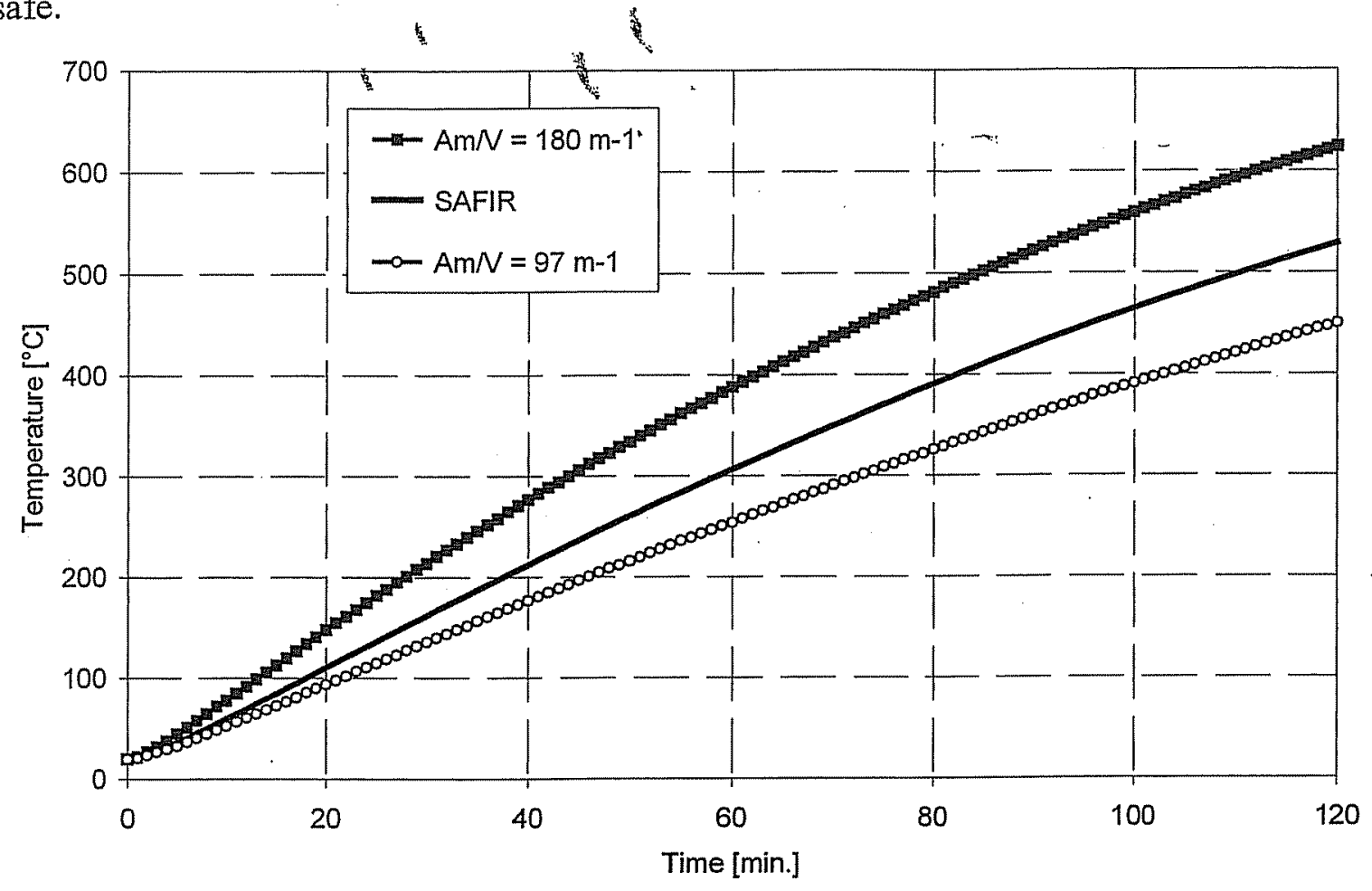

Figure 17 : evolution of the temperature in the protected joint

Figure 18 shows the evolution of the tension strength in the bar, first according to the temperature computed by SAFIR and considering the net section of $12 \times 110=1320 \mathrm{~mm}^{2}$, then calculated on the base of the simple temperature in the bar and on the gross section of $12 \times 150=1800 \mathrm{~mm}^{2}$.

It can be observed that the procedure recommended by Eurocode to neglect the reduction in section of the bars at the locations of the fasteners is not safe when the temperature simply calculated is not sufficiently lower than the 'true' temperature, i.e. namely during the first moments of the fire ( 90 minutes for the case of Figure 18) and also for longer durations when the temperatures in the whole structure tend to level off to a same uniform level because of the tendency of nominal fire curves to end up in a quasi steady state constant temperature (not seen on Figure 18). 


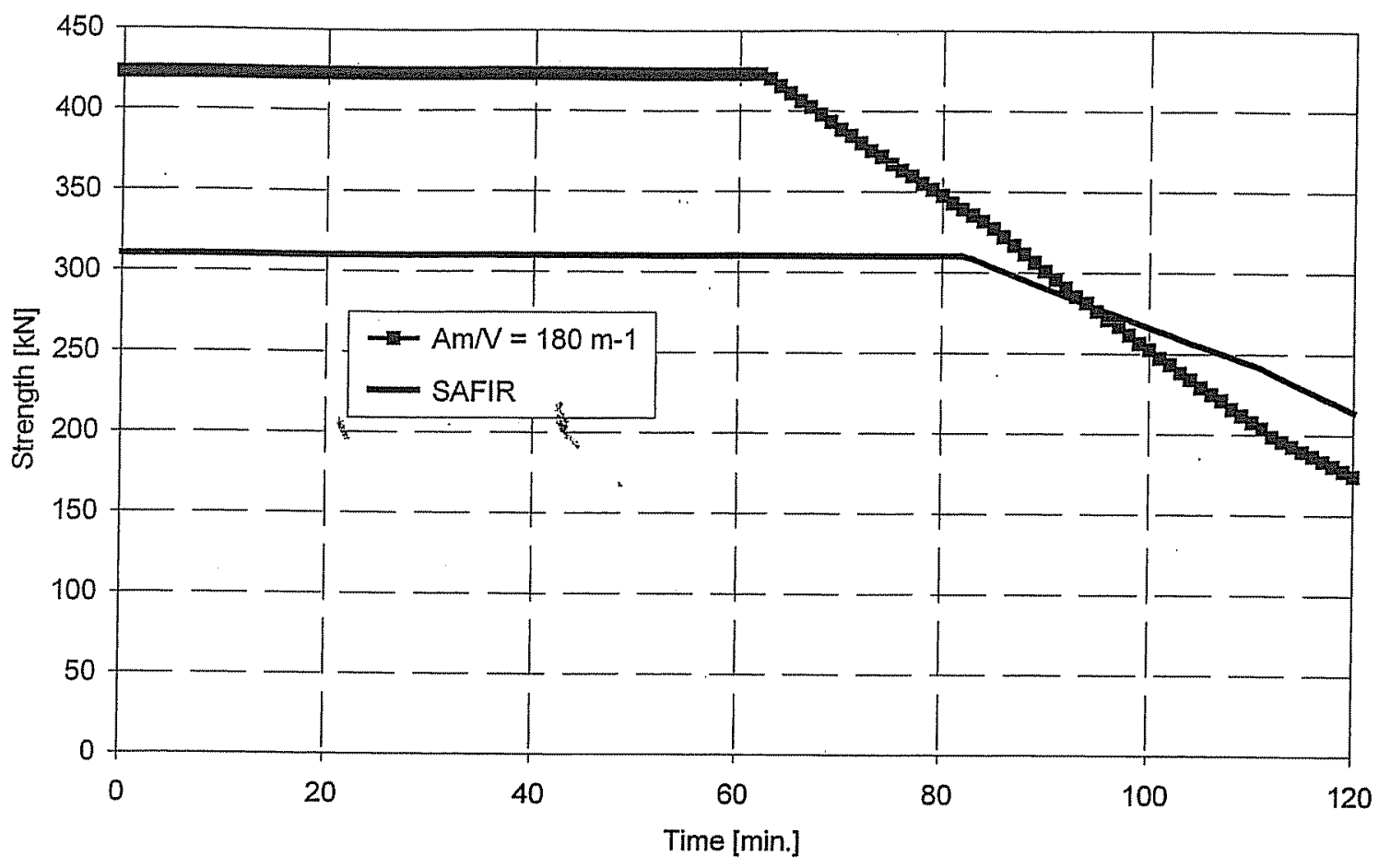

Figure 18 : evolution of the strength in the protected joint

\section{Beam in bending - cover plates}

Figure 19 shows $1 / 8$ of a thermally protected joint in an IPE 330 steel beam subimitted to bending and to shear. The joint is made of $20 \mathrm{~mm}$ bolts and $6 \mathrm{~mm}$ thick steel plates.

If calculated by the simple method based on the local massivity, the temperatures after 90 minutes of ISO fire are;

- $552^{\circ} \mathrm{C}$ in the steel beam $\left(A_{m} / V=200 \mathrm{~m}^{-1}\right)$

- $400^{\circ} \mathrm{C}$ in the cover plate on the flanges $\left(A_{m} / V=114 \mathrm{~m}^{-1}\right)$

- $373^{\circ} \mathrm{C}$ in the cover plates on the web $\left(A_{m} / V=103 \mathrm{~m}^{-1}\right)$

As in the joint of Figure 15 that was geometrical simpler, the temperature in this joint is in fact colder than the temperature calculated in the element by the simple method, but the temperature in the different parts of the joint is significantly higher than the temperature calculated on the base of the local massivity. It can even be observed that the temperature on the plate covering the web is higher than the temperature covering the flange, whereas the local massivity should indicate the contrary; this is of course because of the influence of the thin web that is surrounding this part of the joint. 


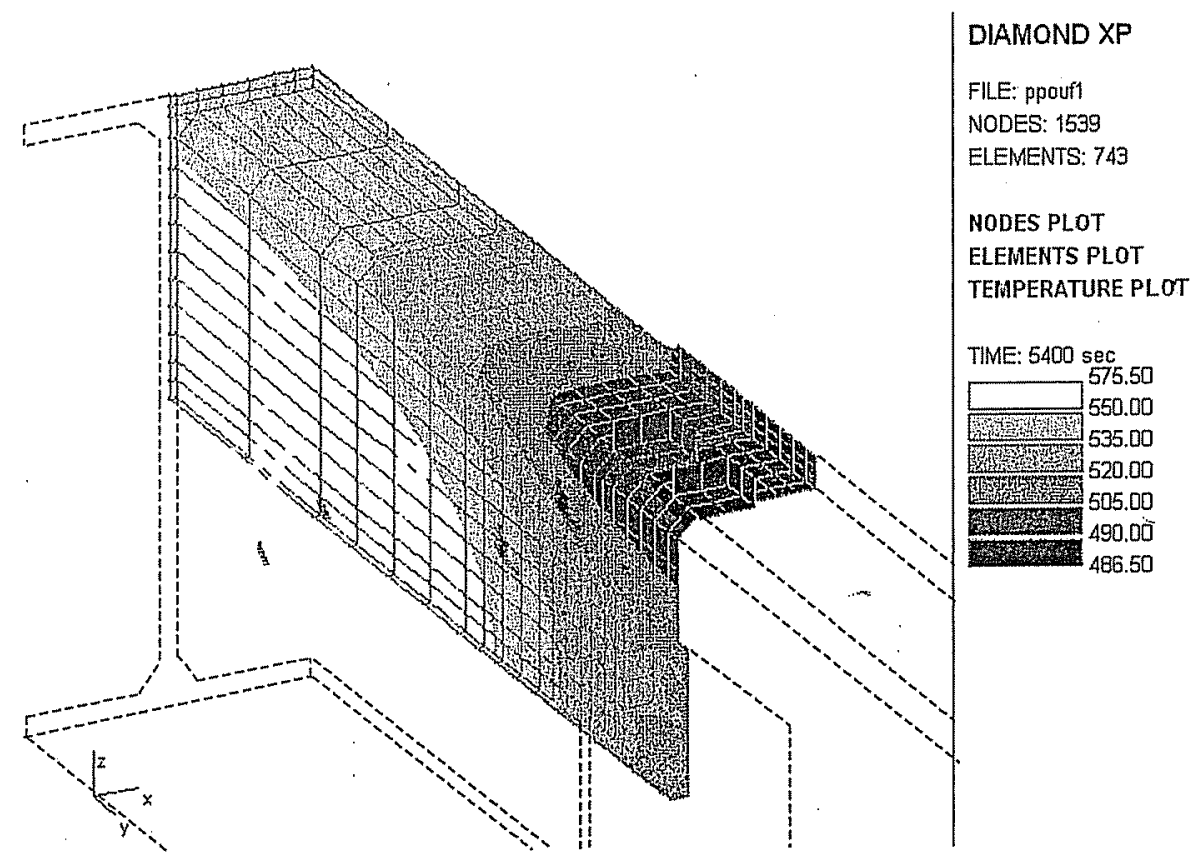

Figure 19 : beam with cover plates - protected

The same holds for the unprotected beam, see Figure 20; the temperatures in the joint are higher than the temperature calculated on the base of the local massivity, namely $633^{\circ} \mathrm{C}$ in the plate on the web and $654^{\circ} \mathrm{C}$ in the plate on the flange.

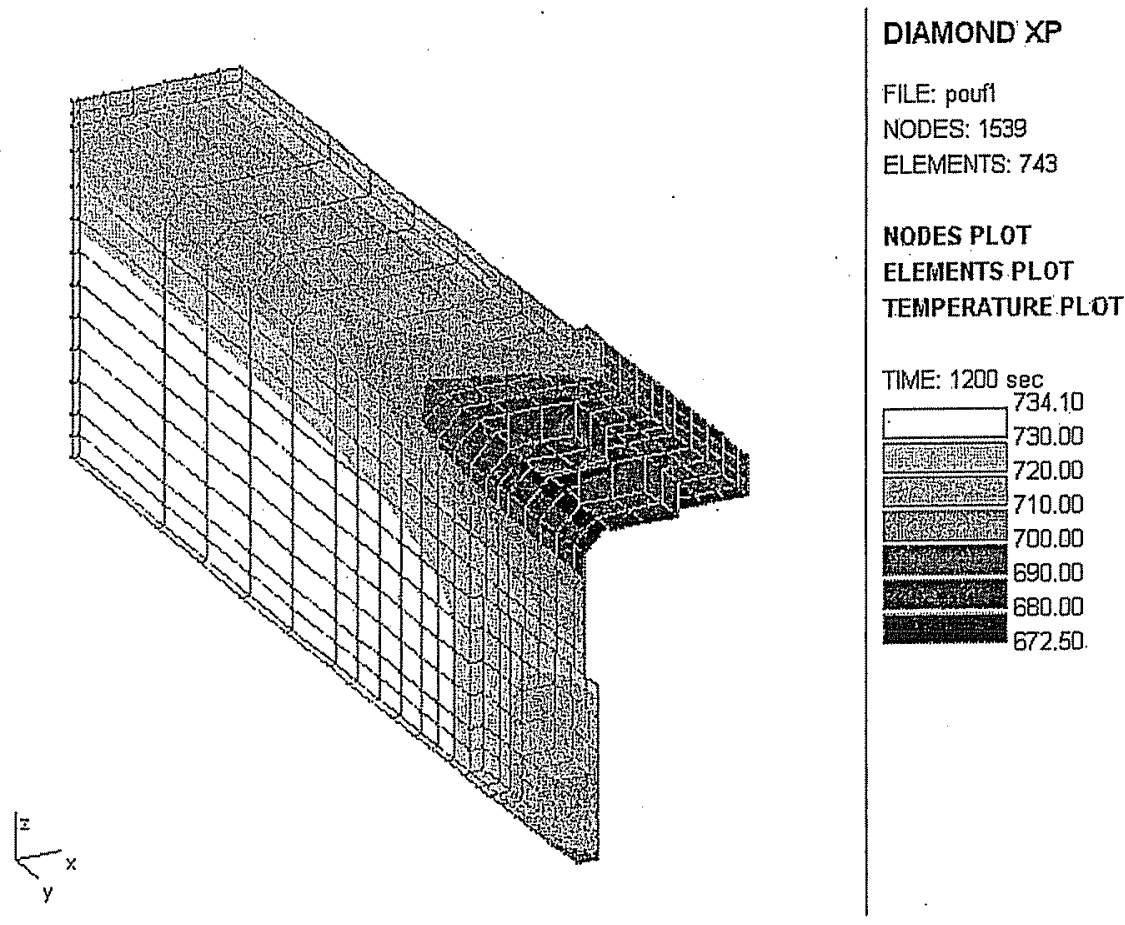

Figure 20 : beam with cover plates - unprotected 


\section{Beam in bending - flush end plates}

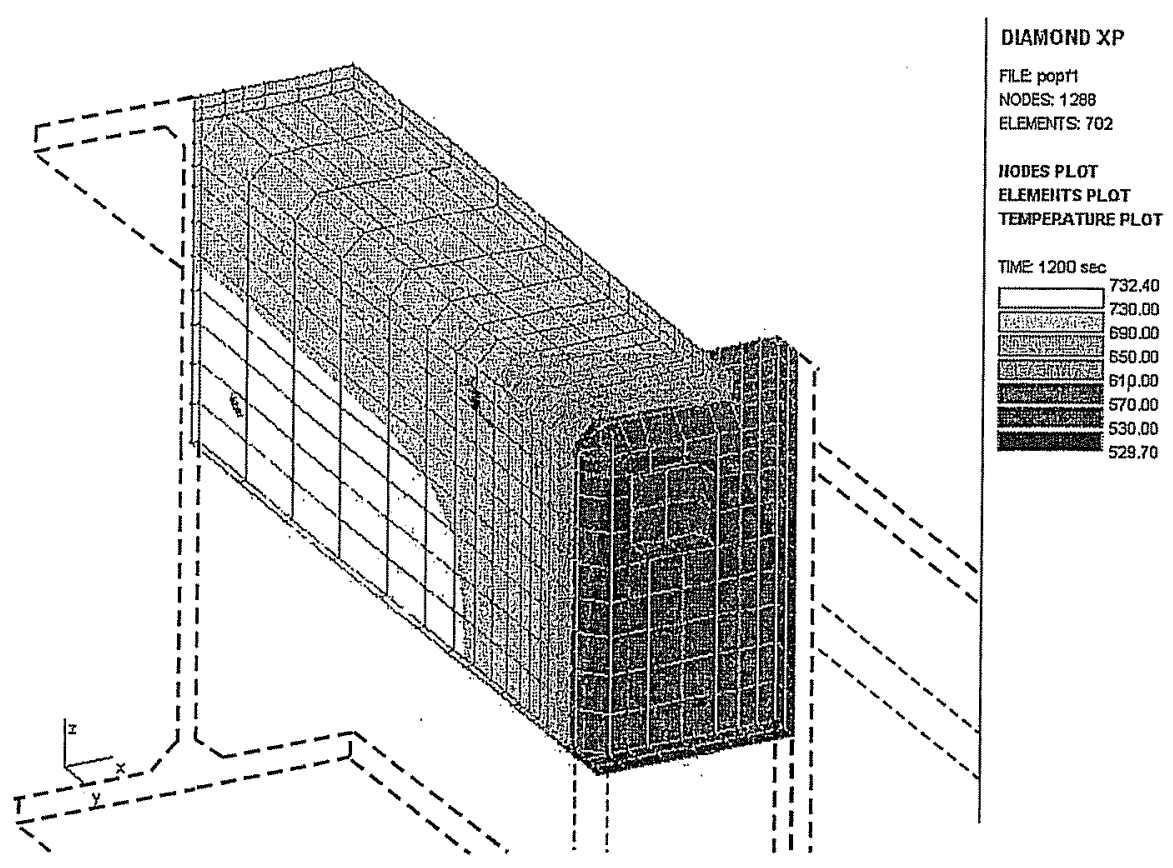

Figure 21 : unprotected flush end plate

Figure 21 is about two IPE360 beams with welded flush end plates connected by $24 \mathrm{~mm}$ bolts. The steel plates are $20 \mathrm{~mm}$ thick and $20 \mathrm{~mm}$ wider in each transverse dimension than the beam section.

Calculated according to the simple method based on the local massivity, the temperatures after 20 minutes of ISO fire are;

$719^{\circ} \mathrm{C}$ in the beam $\left(A_{m} / V=186 \mathrm{~m}^{-1}\right)$

$445^{\circ} \mathrm{C}$ in the plates $\left(A_{m} / V=50 \mathrm{~m}^{-1}\right)$

Here also, the temperature in the connection is lower than the simple temperature in the elements, but significantly higher than the temperature calculated by the simple method based on the local massivity. 


\section{Beam to column joint -flush end plates}

Two IPE360 beams are connected by flush end plates to a HEA240 column. The joint is a moment resisting joint but no stiffener is provided. The end plates are $20 \mathrm{~mm}$ thick and $20 \mathrm{~mm}$ wider in each transverse dimension than the beam. $20 \mathrm{~mm}$ bolts are used to connect the end plates to the flanges of the column.

Figure 22 shows the isotherms after 120 minutes of ISO fire in 1/8 of the protected joint. Simply calculated temperatures are:

$634^{\circ} \mathrm{C}$ in the beam $\left(A_{n} / V=186 \mathrm{~m}^{-1}\right)$

$621^{\circ} \mathrm{C}$ in the column $\left(A_{n t} / V=178 \mathrm{~m}^{-1}\right)$

$389^{\circ} \mathrm{C}$ in the plates $\left(A_{m} / V=77 \mathrm{~m}^{-1}\right)$

It has to be noted that the local massivity calculated simply on the base of the cumulated thickness of the plate and of the flange of the column would yield $A_{m} / V=2 /$ $0.032=63 \mathrm{~m}^{-1}$ and a temperature of $340^{\circ} \mathrm{C}$. Here, the local massivity has been evaluated on the base of a horizontal section through these 2 pates, taking into account the additional lateral surfaces.

Here again, the temperature in the joint is lower than the temperature simply calculated in both connected members, but the temperature is higher than the temperature calculated on the base of the local massivity.

\section{Beam to column joint-angles}

Figure 23 represents the isotherms after 20 minutes of ISO fire in an unprotected joint connecting the IPE360 beams to the HEA240 column. The bolts are M20 bolts. The angles or cleats are $14 \mathrm{~mm}$ thick, $240 \mathrm{~mm}$ wide and 140/65 $\mathrm{mm}$ long.

Simply calculated temperatures are:

$719^{\circ} \mathrm{C}$ in the beam $\left(A_{m} / V=186 \mathrm{~m}^{-1}\right)$

$716^{\circ} \mathrm{C}$ in the column $\left(A_{n} / V=178 \mathrm{~m}^{-1}\right)$ 


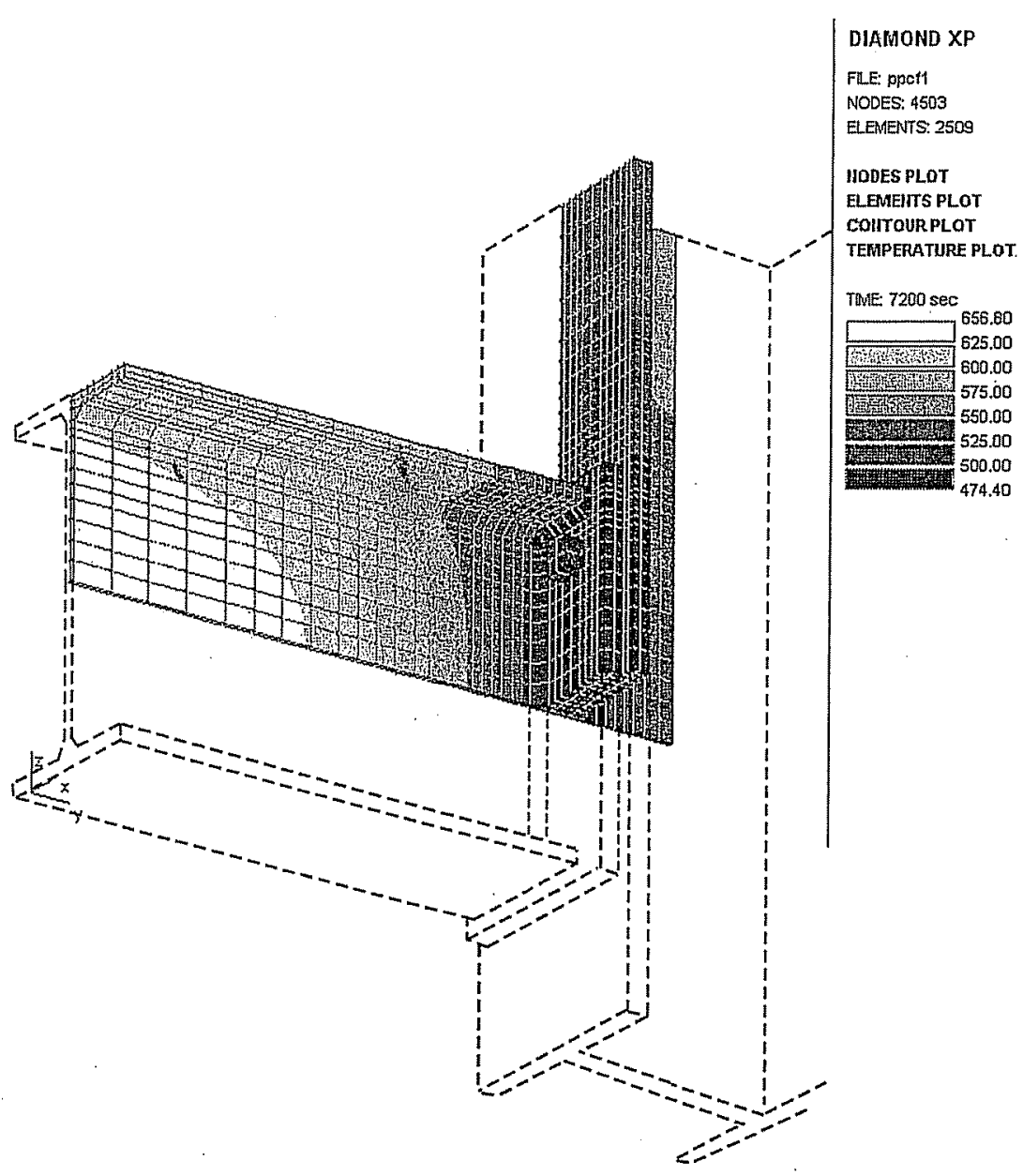

Figure 22 : protected flush end plate

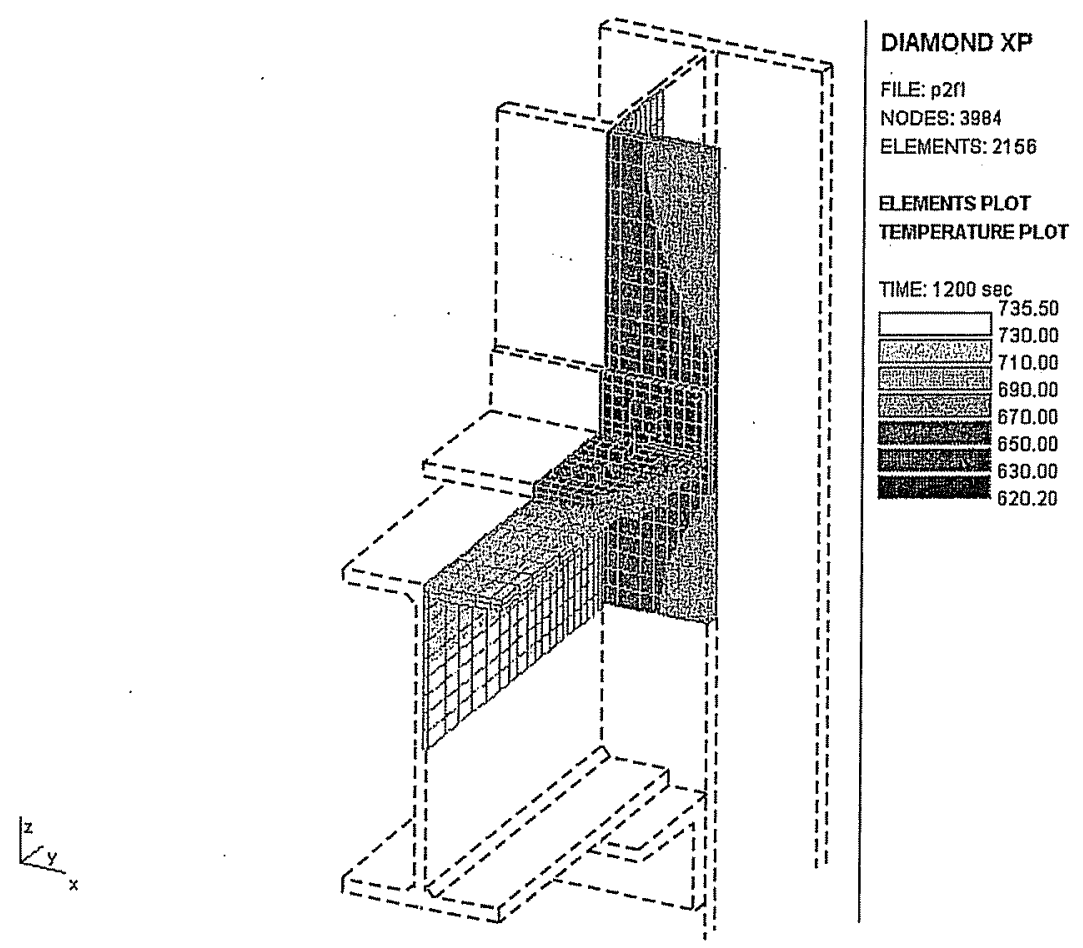

Figure 23 : unprotected joint with angles 


\section{Beam to column joint-flush end plate and stiffener}

Figure 24 refers to a protected joint connecting the IPE360 beam with the HEA240 column with $24 \mathrm{~mm}$ thick flush end plates and $12.7 \mathrm{~mm}$ thick stiffeners between the flanges of the column.

Temperatures calculated by the simple method after 90 minutes of ISO fire in 1/8 of the protected joint are are:

$532^{\circ} \mathrm{C}$ in the beam $\left(A_{m} / V=186 \mathrm{~m}^{-1}\right)$

$520^{\circ} \mathrm{C}$ in the column $\left(A_{m} / V=178 \mathrm{~m}^{-1}\right)$

$269^{\circ} \mathrm{C}$ in the end plates $\left(A_{m} / V=64 \mathrm{~m}^{-1}\right)$

$485^{\circ} \mathrm{C}$ in the stiffeners $\left(A_{m}^{2} / V=157 \mathrm{~m}^{-1}\right)$,

In this case, it is found that the temperature in the end plates is higher than the simply calculated temperature, but the temperature in the stiffener is lower than the simply calculated temperature.

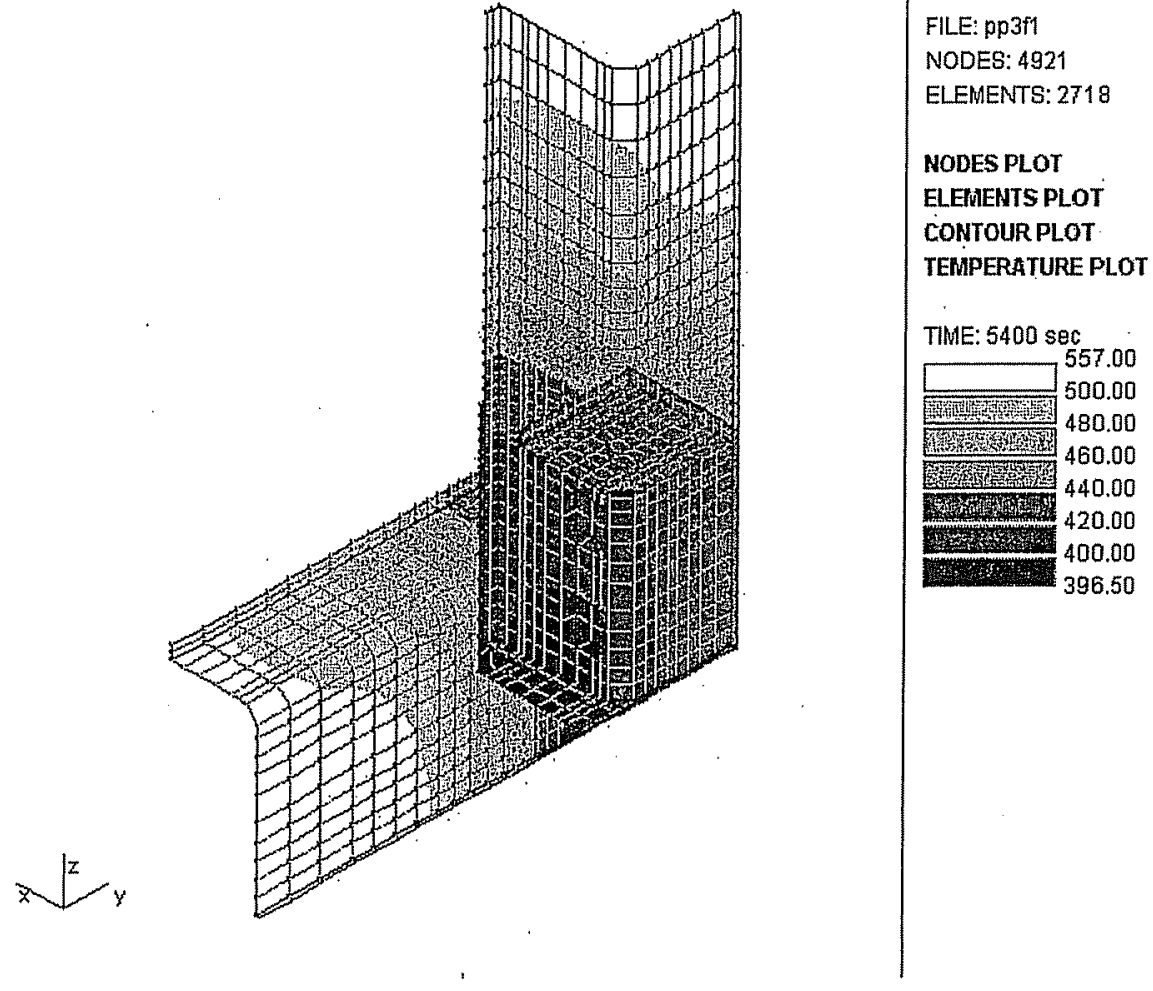

Figure 24 : protected joint with flush end plate and stiffeners 


\section{Beam to column joint-angles and stiffener}

Figure 25 is a joint between the IPE360 beams and HEA240 column made of bolted cleats and involving stiffeners between the flanges of the column. The thickness of the stiffener is $12.7 \mathrm{~mm}$. The thickness of the cleats is $14 \mathrm{~mm}$ for the connection to the flanges of the beams and $10 \mathrm{~mm}$ for the connection to the web of the beams.

The figure shows the isotherms after 30 minutes of ISO fire in this joint without thermal protection. They have to be compared with:

$809^{\circ} \mathrm{C}$ in the beam $\left(A_{m} / V=186 \mathrm{~m}^{-1}\right)$

$805^{\circ} \mathrm{C}$ in the column $\left(A_{x+1} / V=178 \mathrm{~m}^{-1}\right)$

$732^{\circ} \mathrm{C}$ in the cleats on the flanges of the beam $\left(A_{m} / V=87 \mathrm{~m}^{-1}\right)$

$792^{\circ} \mathrm{C}$ in the stiffeners $\left(A_{m} / V=157 \mathrm{~m}^{-1}\right)$

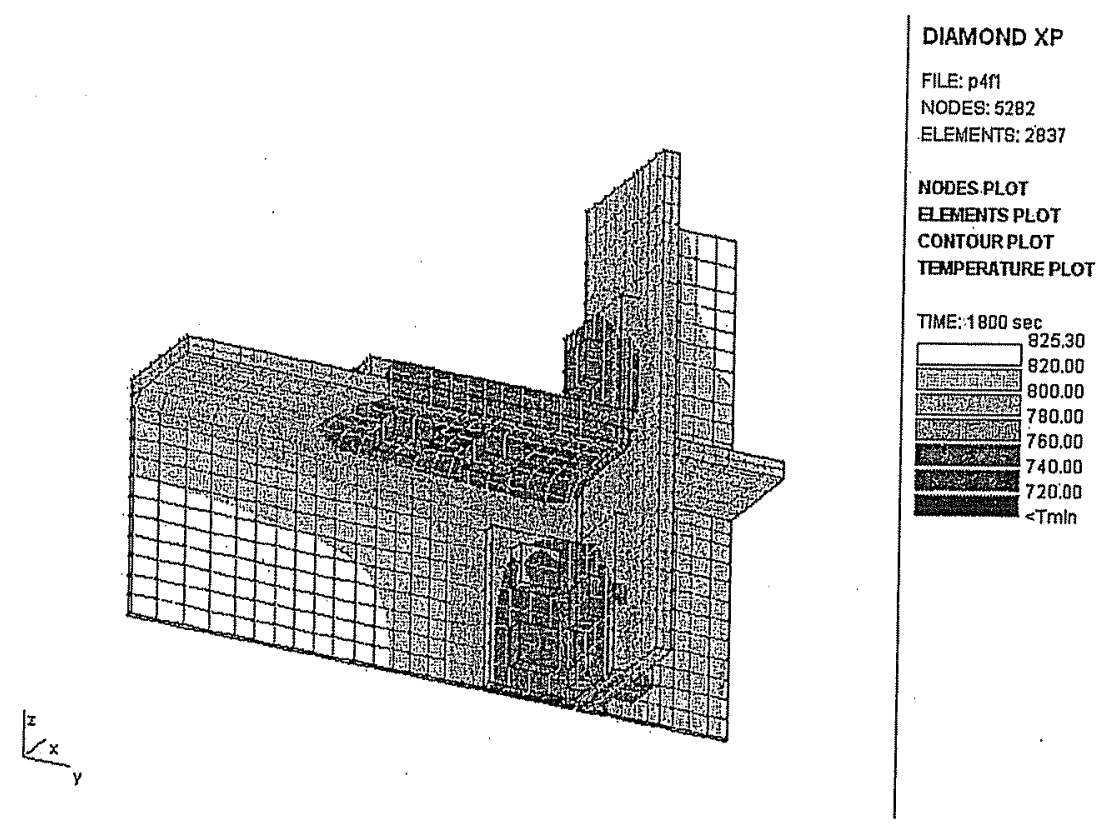

Figure 25 : unprotected joint with cleats and stiffener

It has to be noted that the results of the simulation made on the two joints of Figure 24 and Figure 25 have been compared with experimental results obtained by Kruppa [5]. The agreement was generally quite good, with a tendency for the experimental temperatures to be somewhat lower than the numerically calculated values in the joints, owing to a corner effect in the testing compartment. These comparisons can not be shown here because of the limited amount of allocated space for each paper. 


\section{CONCLUSIONS}

From all the examples that have been calculated, there has been no single occurrence where the temperature in the joint would have been higher than the temperature of the connected elements. This result was obtained although the favourable effect of colder temperatures in the corners of the compartment which can play a role in most of the cases has not been taken into account. It is therefore indeed safe to design the connection on the base of the temperature calculated in the connected elements.

The recommendation of Eurocode $3 \times[1]$ that net-section failure at fasteners holes need not be considered cannot be supported hecause, after an important cluration of exposure to a fire curve that has a tendency to reach a nearly steady state condition - such as the nominal fire curves - there is a tendency for the temperature to become more and more uniform and, hence, the effect of additional material near the hole is very much diluted. Furthermore, this local effect of the fastener can be negative in some cases, namely when the diameter of the bolt is smaller that the total thickness of the plates that the bolt connects.

The recommendation that the temperature of a connection may be assessed using the local massivity value of the components comprising the connection can also not be supported. In nearly all calculated examples, the temperature in the components was higher than what the local massivity would have indicated. This is probably because the dimensions of the components are of an order of magnitude smaller than the dimensions of the connected members and the influence of these members is felt in the components.

\section{REFERENCES}

[1] Draft prEN 1993-1-2, Eurocode 3: Design of steel structures - Part 1-2: General rules Structural fire design, Third preliminary draft, May 2001.

[2] ENV 1991-1-2, Eurocode 1- Basis of design and actions on structures - Part 2-2: Actions on structures - Actions on structures exposed to fire, [3] ENV 1993-1-2, Eurocode 3: Design of steel structures - Part 1-2: General rules - Structural fire design, CEN, Brussels, May 1995.

[3] ENV 1993-1-2, Eurocode 3: Design of steel structures - Part 1-2: General rules Structural fire design, CEN, Brussels, May 1995.

[4] Franssen J.-M., Kodur V. K. R. \& Mason J., User's Manual for SAFIR (Version NZ). A Computer Program for Analysis of Structures Submitted to the Fire, Univ. of Liege, Ponts et Charpentes, Rapport interne SPEC/2000_03, 2000

[5] J. Kruppa, Résistance au feu des assemblages par boulons haute résistance, C.T.I.C.M., Puteaux, France, June 1976. 


\title{
EXPERIMENTAL AND ANALYTICAL STUDIES OF STEEL JOINT COMPONENTS AT ELEVATED TEMPERATURES \\ 1 \\ 娄
}

Spyros SPYROU ${ }^{1}$, Buick DAVISON ${ }^{1}$ lan BURGESS ${ }^{1}$ Roger PLANK ${ }^{2}$

1 Department of Civil and Structural Engineering, University of Sheffield, Sheffield S1 3JD, UK

2 School of Architectural Studies, University of Sheffield, Sheffield S10 2TN, UK

\begin{abstract}
This paper reports on experimental furnace testing and development of simple analytical models intended to initiate the development of a Component Method for modelling of steel beam-to-column connections in fire conditions. The basic theme of the Component Method is to consider any joint as an assembly of individual simple components. Each of these components is simply a non-linear spring, possessing its own level of strength and stiffness in tension, compression or shear, and these will degrade as its temperature rises.

The main objective of this study was to investigate experimentally and analytically the behaviour of tension and compression zones of end-plate connections at elevated temperatures. A series of experiments has been carried out, and these are described in the paper. Simplified analytical models of the component behaviour have been developed, and these have been validated against the tests and against detailed finite element simulations. The simplified models have been shown to be very reliable for this very common type of joint, although similar equations will need to be developed for other configurations. The component models developed have been shown to produce moment-rotation curves which correlate well with the results of previous furnace tests on complete connection behaviour in fire. The principles of the Component Method can be used directly in either simplified or finite element modelling, without attempting to predict of the overall joint behaviour in fire. This will enable semi-rigid behaviour to be taken into account in the analytical fire engineering design of steel-framed buildings, for which it is inadequate simply to consider the degradation of the ambient-temperature moment-rotation characteristics of a joint without taking account of the high axial forces which also occur.
\end{abstract}

KEYWORDS: fire engineering, joints, component method, steel structures, furnace testing, simplified modelling, FE modelling. 